\title{
Invasive predators induce plastic and adaptive responses during embryo development in a threatened frog
}

\author{
Martina Muraro ${ }^{1}$, Samuele Romagnoli ${ }^{1}$, Benedetta Barzaghi ${ }^{1}$, \\ Mattia Falaschi ${ }^{1}$, Raoul Manenti ${ }^{1}$, Gentile Francesco Ficetola ${ }^{1,2}$
}

I Department of Environmental Science and Policy, Università degli Studi di Milano, Via Celoria 10, 20133 Milan, Italy 2 Univ. Grenoble Alpes, CNRS, Univ. Savoie Mont Blanc, Laboratoire d'Écologie Alpine (LECA), F-38000 Grenoble, France

Corresponding author: Martina Muraro(marti.muraro93@gmail.com)

Academic editor: Gregory Ruiz | Received 3 March 2021 | Accepted 11 November 2021 | Published 8 December 2021

Citation: Muraro M, Romagnoli S, Barzaghi B, Falaschi M, Manenti R, Ficetola FG (2021) Invasive predators induce plastic and adaptive responses during embryo development in a threatened frog. NeoBiota 70: 69-86. https://doi. org/10.3897/neobiota.70.65454

\begin{abstract}
Invasive predators can strongly affect native populations. If alien predator pressure is strong enough, it can induce anti-predator responses, including phenotypic plasticity of exposed individuals and local adaptations of impacted populations. Furthermore, maternal investment is an additional pathway that could provide resources and improve performance in the presence of alien predators. We investigated the potential responses to an alien predator crayfish (Procambarus clarkii) in a threatened frog (Rana latastei) by combining field observations with laboratory measurements of embryo development rate, to assess the importance of parental investment, origin and exposure to the crayfish cues. We detected a strong variation in parental investment amongst frog populations, but this variation was not related to the invasion status of the site of origin, suggesting that mothers did not modulate parental investment in relation to the presence of alien predators. However, cues of the invasive crayfish elicited plastic responses in clutches and tadpoles development: embryos developed faster when exposed to the predator. Furthermore, embryos from invaded sites reached Gosner's development stage 25 faster than those from non-invaded sites. This ontogenetic shift can be interpreted as a local adaptation to the alien predator and suggests that frogs are able to recognise the predatory risk. If these plastic responses and local adaptation are effective escape strategies against the invasive predator, they may improve the persistence of native frog populations.
\end{abstract}

\section{Keywords}

Anti-predator responses, development rate, egg size, parental investment, Procambarus clarkii, Rana latastei, rapid evolution

Copyright Martina Muraro et al.. This is an open access article distributed under the terms of the Creative Commons Attribution License (CC BY 4.0), which permits unrestricted use, distribution, and reproduction in any medium, provided the original author and source are credited. 


\section{Introduction}

Biological invasions are a major threat to biodiversity and exert multiple impacts on the ecosystems on a global scale (Bellard et al. 2016, Nentwig et al. 2018). Invasive predators often cause declines and extinctions of native species (Mooney and Cleland 2001). These negative impacts have been often explained by the lack of common evolutionary history, which can hamper predator recognition in native prey and can limit the expression of effective anti-predator responses (Sih et al. 2010). However, there are several mechanisms that allow native species to implement effective responses against invasive predators (e.g. Freeman and Byers 2006; Weis and Sol 2016; Falaschi et al. 2020).

First, prey can display plastic responses to predator selective pressures acting on morphological, life history, physiological and behavioural features (Peacor et al. 2006, Nunes et al. 2014a, Melotto et al. 2021a). Prey generally express phenotypic plasticity when they are able to recognise the alien predator, for instance, because it shares cues with a native predator or is phylogenetically similar to it (Ferrari et al. 2007). Furthermore, aliens can drive strong selective pressures that induce genetic changes in native populations and may determine an evolutionary response of the prey (Cousyn et al. 2001, Nunes et al. 2014a, Ortega et al. 2017, Melotto et al. 2020). If responses to invasive predators are effective, they may increase prey fitness and, ultimately, can allow long-term persistence of native populations. In addition, in some cases, parents can improve the fitness of their offspring through the modulation of parental investment (Cameron and Martin 2000). Parental investment allows modulating the phenotype of offspring on the basis of the conditions experienced by parents (Pick et al. 2019). In many oviparous taxa, egg volume is a major form of parental investment affecting key traits of offspring's fitness, such as survival, morphology, stress tolerance, growth and development rate (Mousseau 1998). Nevertheless, the actual usefulness of a parental investment can be highly context dependent and the increase in parental investment is not necessarily associated with a rise in offspring fitness. Indeed, females may not be able to predict the environment in which their offspring will grow, thus the invested resources would be not appropriate to it (Kaplan 1992). While the selective pressures exerted by invasive species can promote the quick evolution of behavioural and morphological traits limiting exposure to predation (Skelly and Freidenburg 2000, Melotto et al. 2020), there is little information available on the role played by parental investment. Importantly, the effectiveness of parental investments in allowing native prey species persistence remains an open question.

Amphibians are an excellent model system to assess plastic and evolutionary responses and to evaluate the role of parental investment, as they show a broad diversity of phenotypic plasticity, they can rapidly adapt to strong selective pressures and many species are easy to handle under experimental rearing conditions (Kaplan 1998, Relyea 2001, Beebee 2005, McCartney-Melstad and Shaffer 2015). For instance, frogs lay clutches that display a strong variation in number of eggs and egg size and these traits are commonly used to determine the parental investment (Kaplan and King 1997); clutch features are closely related to female body condition and to the environment 
experienced by mothers (e.g. Dziminski and Ross 2005, Sinsch et al. 2015). Populations of native amphibians exposed to invasive predators often show strong variation in developmental rate. For instance, populations of the Italian agile frog (Rana latastei) came into contact with the American red swamp crayfish (Procambarus clarkii) in northern Italy approximately 20 years ago (Lo Parrino et al. 2020). The red swamp crayfish exerts a strong predator pressure on amphibians, inasmuch as it is a voracious predator on larvae of amphibians (Cruz et al. 2006, Ficetola et al. 2011b). This invasive crayfish also feeds on amphibian eggs and is able to separate eggs from their protective jelly (Gherardi et al. 2001, Renai and Gherardi 2004). This alien predator is listed amongst the "100 worst" invasive alien species in the world (Cruz et al. 2008, Nentwig et al. 2018). Recent research showed that the Italian agile frog tadpoles are able to metamorphose earlier when exposed to the red swamp crayfish in experimental conditions, especially when belonging to populations already invaded (Melotto et al. 2020). This suggests that both phenotypic plasticity and local adaption can accelerate tadpole development in order to limit exposure to invasive predators (Melotto et al. 2020). However, in invaded populations, the faster development is expected to require higher energetic investments for growth and anti-predator behaviours (Burraco et al. 2020, Melotto et al. 2020). Parental investments might allow parents to partially counteract the constraints posed by the red swamp crayfish. Furthermore, we do not have information on potential responses of early development stages, even though the rate of embryo development can be modulated to reduce predation pressure (Warkentin 2005).

The aim of this study is to test the role of parental investment, phenotypic plasticity and adaptations in the interactions between alien predator and native populations and to evaluate whether parents are able to modulate their investment in response to the presence of an alien predator in Rana latastei. We first tested: i) whether variability in parental investment exists amongst frog populations and ii) if this could be related to the invasive crayfish presence as a modulation of maternal investment. Furthermore, iii) we tested whether, under controlled conditions, the rate of embryo development is related to differences in parental investment, whether it is faster in populations invaded by the crayfish (potential local adaptations) or when exposed to the crayfish (potential phenotypic plasticity).

To test these hypotheses, we measured several features of egg clutches to evaluate the variability in parental investment between frog populations invaded and not invaded by the crayfish. Subsequently, we used a common rearing experiment to measure differences in development rates across clutches and tadpoles with different origin, parental investment or exposed/unexposed to the red swamp crayfish. As different climate conditions seem to affect clutch laying in anurans and to avoid differences in parental investment and development time amongst populations living in different climatic conditions (Ficetola and Bernardi 2005), we selected multiple populations from the same altitude and with similar local climate. Our study underlines the importance of phenotypic plasticity and rapid adaptation for anti-predator responses during biological invasions. 


\section{Methods}

\section{Study system.}

The target species of this study is the Italian agile frog (Rana latastei), which lives from the sea level up to $500-700 \mathrm{~m}$ a.s.l. This frog is endemic of northern Italy and nearby areas and is listed by IUCN as vulnerable due to habitat reduction and fragmentation, pollution and alien species introduction of breeding sites (Schmidt et al. 2020). Rana latastei females produce their globular clutches from February to mid-April. Each Rana latastei female lay a single egg mass that displays strong variability, with the number of eggs per clutch ranging from 300 to $>2700$ eggs (Bernini et al. 2007, Ambrogio and Mezzadri 2018). Clutches are laid in ponds and ditches surrounded by woods and they hatch in 12-15 days, while tadpoles metamorphose in about 3 months. Variation in parental investment (egg size) is known to influence multiple fitness-related traits of larvae, including survival and growth rate (Ficetola and De Bernardi 2009, Ficetola et al. 2011a).

The red swamp crayfish, Procambarus clarkii, is native from eastern North America and Mexico, but has been introduced worldwide (except in Australia and Antarctica). This crayfish was introduced in Italy thirty years ago and, since then, its range showed an impressive expansion. Nowadays Procambarus clarkii is widespread in Italy and it invaded the study area between 2005 and 2009 (Lo Parrino et al. 2020, Melotto et al. 2020). Landscape-level analyses have shown that the crayfish has strong effects on frog populations, reducing tadpole survival in the wild and affecting the dynamics of population networks (Ficetola et al. 2012, Manenti et al. 2020, Falaschi et al. 2021).

We studied frog populations living in the foothills of the Lombardy Region (north-western Italy). To avoid differences amongst populations living in different microclimatic conditions (Morrison and Hero 2003, Ficetola and Bernardi 2005), we focused on foothill populations living at an altitude of 177-295 m above sea level (a.s.l) within the Monza-Brianza, Como and Lecco Provinces (Suppl. material 1: Table S1). To confirm that the variability amongst clutches in parental investment is unrelated to variation of climatic conditions, we downloaded the ChelsaClim maps at 30-arc second resolution (Karger et al. 2017) and analysed them with QGIS 3.4.13 (https:// qgis.org/). We considered two key climatic parameters, known to affect frog fitness and phenology: monthly precipitation and annual mean temperature (Ficetola and Maiorano 2016). The study area is heavily populated, but this region also hosts several fragmented broadleaved forests and wetlands. Within the study area, we sampled eight breeding sites. Each site was represented by a wetland (either a pond or a ditch); all clutches from the same wetland were $<50 \mathrm{~m}$ from each other. Four of the eight sites considered are colonised by Procambarus clarkii, while four are crayfish-free.

\section{Clutch sampling and measurement of parental investment.}

Field activities were performed in February 2020, at the beginning of the breeding season of the Italian agile frog. Sites were monitored daily to collect egg clutches laid during the night before. Newly-laid clutches were photographed in the field to obtain two 
measures of maternal investment: number of eggs and egg volume. To take pictures, egg masses were removed from the ponds and gently divided in smaller fragments ( $4 \pm$ 1.5 SD, fragments per clutch) to make eggs individually distinguishable. Clutch fragments were positioned on a white support (mobile table top) wet with the water of the breeding sites. A ruler was placed above the support and photographs were taken with the help of a camera, equipped with a macro lens. The clutch fragments were returned to the breeding sites, except for two small fragments per clutch, which were brought to the laboratory for the common rearing experiment. Overall, we obtained pictures from 50 clutches (total number of pictures processed: 223). We then used ImageJ (Schindelin et al. 2015) to measure the number of eggs and to estimate egg volume $\left(\mathrm{cm}^{3}\right)$. To count the number of eggs, the photographs were taken in black and white because the Analyze Particles function requires binarised photographs (Moraga and Pervin 2018). We then used the Threshold function to adjust the photos contrast and the Analyze Particles function to automatically count them and to calculate the average diameter of eggs. Egg volume was then calculated assuming a spherical shape. Finally, the value of total parental investment of each clutch was calculated as total number of eggs $x$ average egg volume.

\section{Development and survival under common rearing conditions}

We set up a common rearing experiment to measure differences in development and survival across clutches with different origin, parental investment or exposed/unexposed to the crayfish. We used the same experimental set elaborated by Melotto et al. (2020). Two small fragments ( $40 \pm 12$ eggs) from each of the 50 sampled clutches were transported in the laboratory the day after deposition. The two fragments from the same clutch were randomly assigned to one of two treatments: absence of the crayfish or non-lethal presence of the crayfish. The fragments of the clutches were housed in containers and containers were stored in six $70 \mathrm{x} 48 \mathrm{~cm}$ blocks filled with aged tap water. Clutches belonging to the same blocks were arranged nearby the same central compartment. In half of the blocks, we placed one adult crayfish in the central compartment (predator treatment), while in the remaining blocks, the central compartment was empty (controls). The containers hosting the clutches were separated from the crayfish area by a fine wire mesh that allowed the flow of chemical and visual cues by the crayfish. Control and experimental blocks were maintained under identical outdoor conditions; the three crayfishes were randomly re-assigned to the experimental blocks every 7 days. Half of the water in the blocks was changed weekly and crayfish were fed with flaked fish food and rabbit pellets. The containers were monitored daily to record the timing of hatching (as average time elapsed between the hatching of the first and last tadpoles of the fragment) and the reaching of Gosner's stage 25 (i.e. freeswimming tadpole) (Gosner 1960).

Due to the COVID-19 pandemic, it was not possible to complete the research as originally conceived, because a total local lockdown, starting on 9 March 2020, caused the interruption of laboratory activities. However, despite that, we collected 100 fragments; it was possible to measure hatching time for 42 fragments only (18 
collected from sites crayfish-free and 24 colonised by the predator), taken from five ponds. Finally, we determined the time to reach Gosner's stage 25 in 239 larvae: 116 developed with Procambarus clarkii non-lethal presence and 123 without crayfish in the rearing experiment.

\section{Data analyses}

A linear mixed effects model was used to determine if there was a correlation between number of eggs and egg volume within populations; site of origin was included as the random effect. Adding population as the random factor allowed us to consider differences between populations when analysing variation within populations. We used Pearson's Correlation test to analyse whether there is a covariation between the average number of eggs and the average egg volume of each population. The inclusion of random effect was not necessary when assessing the relationship across populations, as in this case, we only considered one value (average across all the egg masses) for each population.

To assess differences amongst populations in parental investment (egg volume, number of eggs and total parental investment), we used three generalised linear models, one for each parameter describing parental investment, including site of origin as the fixed factor. Subsequently, we used linear mixed effects models (LMMs) to determine the factors related to parental investment across populations (egg volume, number of eggs and total parental investment). Invasion status (invaded/non-invaded by the crayfish), monthly precipitation and annual mean temperature were used as candidate fixed factors with site of origin as the random factor. We then calculated Akaike's Information Criterion (AIC) for all the combinations of fixed independent variables (invasion status and climatic parameters). The model with the lowest AIC value is the one that explains the most variation with the fewest variables and is considered to be the "best model" (Burnham and Anderson 2002). In all models, number of eggs and total investment were log-transformed to improve normality.

LMMs were also used to test factors affecting average hatching time and the time required to reach Gosner's stage 25 (free-swimming tadpole). Average egg volume of the fragment, invasion status and treatment (non-lethal exposure to the crayfish vs. no exposure) were the independent variables. In preliminary tests, we also evaluated statistical interactions between invasion status and treatment. However, these interactions were not significant $(p>0.3)$; consequentially, we excluded them from the analyses. All LLMs included site of origin and rearing block as random factors. We also used the DHARMa R package to assess the residuals of mixed models (Hartig 2021); in all of the analyses, the residuals showed no significant deviations from expectations (for all the models: KS test: $p>0.43$, dispersion test: $p>0.79$ ). We performed all the statistical analyses in R environment, version 3.4.2, (http://www.r-project.org). We used the lme4, lmerTest, car and MuMIn packages for linear mixed models (Kuznetsova et al. 2017) and visreg package (Breheny and Burchett 2017) to generate conditional regression plots. Furthermore, we calculated marginal and conditional $R^{2}$ as a measure of effect size in LMMs (Nakagawa and Schielzeth 2013, Johnson 2014). 


\section{Results}

\section{Parental investment}

Fifty newly-laid clutches were collected and photographed to determine the parental investment for each population. We found a strong variation of parental investment across clutches and populations. The number of eggs per clutch ranged from 500 to 2500, while the average egg volume ranged between 0.003 and $0.008 \mathrm{~cm}^{3}$ (Fig. 1a). The total number of eggs, egg volume and total parental investment showed strong and significant differences amongst frog populations (number of eggs: $\mathrm{F}_{7,39}=6.474, p$ $<0.001$; egg volume: $\mathrm{F}_{7,39}=4.652, p<0.001$; total investment: $\mathrm{F}_{7,39}=6.136, p<0.001$; Figs. 1a, b, c). There was no correlation between number of eggs and egg volume within population $\left(\mathrm{F}_{1,43.6}=-0.247, p=0.812\right)$. Across populations, there was a positive correlation between average number of eggs per clutch and egg volume, but the correlation was not significant at $\alpha=0.05(r=0.681, \mathrm{~N}=8, p=0.063)$.

When we assessed the relationship amongst the three parameters representing parental investment and population features (climate and presence of the crayfish), the null-model always showed lower AIC values, compared to the models including independent variables (Table 1). This suggests that the number of eggs, egg volume and total investment were not related to either climatic parameters or to the presence of the crayfish in the site. Furthermore, none of the independent variables was significantly related to any of the parameters representing maternal investment (Suppl. material 1: Table S2).

\section{Common rearing experiment}

The average hatching time of embryos $( \pm S D)$ was $10.18 \pm 0.83$ days. Hatching time was not related to the average egg volume (mixed model: $\mathrm{F}_{1,32.5}=0.029, p=0.867$; Fig. 2c) or to the occurrence of crayfish in the site $\left(F_{1,18}=2.721, p=0.116\right.$, Fig. 2a). Clutches reared with the crayfish in the block hatched faster than controls $\left(\mathrm{F}_{1,14.6}=\right.$ 10.786, $p=0.005$, Fig. $2 \mathrm{~b}$; no significant interaction between invasion status and treatment: $p=0.227$ ). The model explained a good amount of variation (marginal $R^{2}$ $=0.17$; conditional $R^{2}=0.69$ ).

The average time required for reaching Gosner's stage 25 (free-swimming tadpole) $( \pm S D)$ was $16 \pm 1$ days. Tadpoles from clutches with smaller egg volumes tended to reach Gosner's stage 25 faster than those with a larger volume one $\left(\mathrm{F}_{1,24}=7.138, p=\right.$ 0.013; Fig. 2f) and we detected significant differences between clutches from invaded vs. non-invaded sites, as tadpoles from invaded sites reached stage 25 significantly earlier $\left(\mathrm{F}_{1,13.45}=5.017, p=0.04\right.$; Fig. $\left.2 \mathrm{~d}\right)$. The model explained a good amount of variation (marginal $R^{2}=0.47$; conditional $R^{2}=0.78$ ). However, these results were strongly dependent on the time to reach Gosner's stage 25 of tadpoles hatched from one single clutch fragment with very short time of development. If this fragment was removed from the dataset, the relationship between hatching time and both egg volume and crayfish presence in the ponds of origin become non-significant (egg volume $=\mathrm{F}_{1,23}=$ 

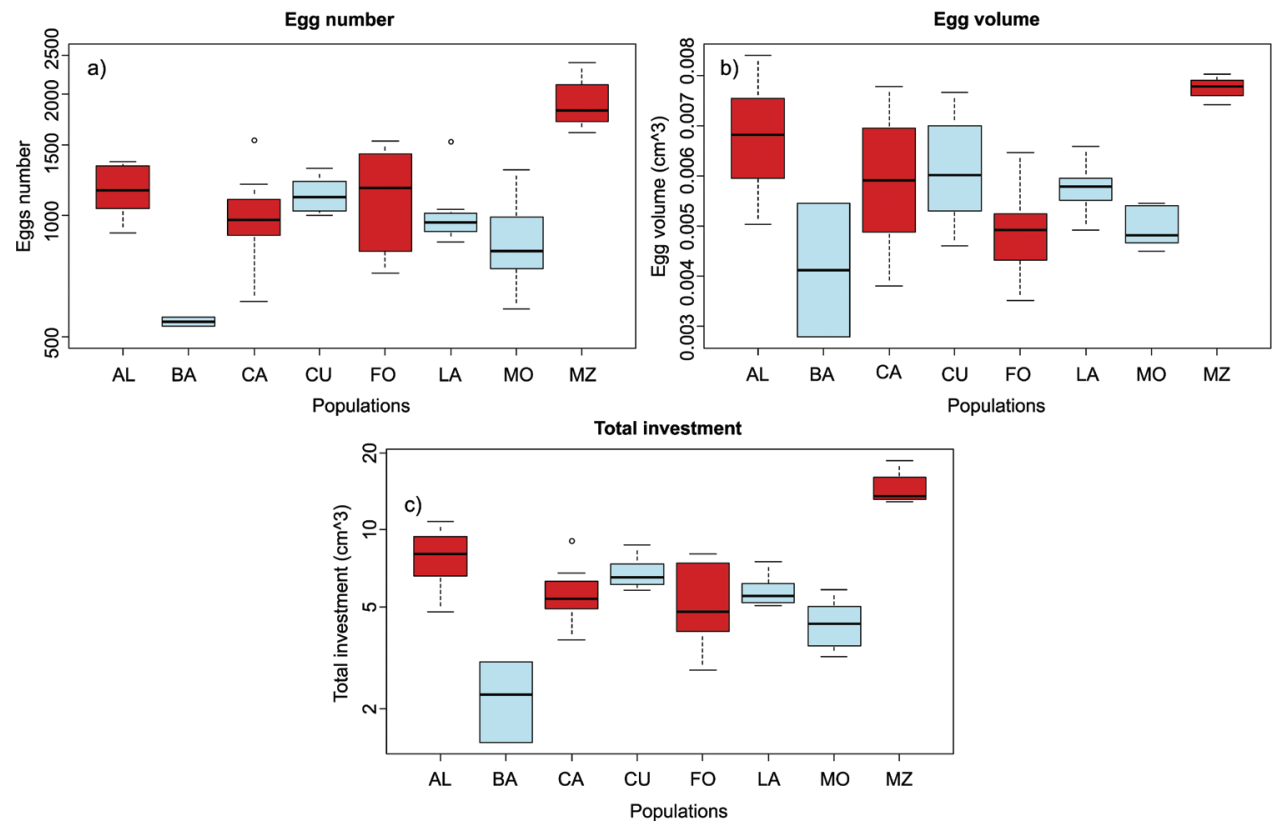

Figure I. Variability of the three parameters considered describing parental investment amongst populations: a egg number $\mathbf{b}$ egg volume; $\mathbf{c}$ total investment (i.e. egg number $\times$ egg volume). Red boxplots represent crayfish presence in the original ponds, while blue boxplots represent crayfish-free sites. $\mathrm{N}=$ 50 clutches. For data analysis, the number of eggs and total investment were logarithm transformed to improve normality; therefore, we show the log-transformed $y$-axis.

$3.442, p=0.077$, crayfish presence $=\mathrm{F}_{1,13}=3.9, p=0.069$ ). Additionally, in this analysis, tadpoles exposed to the crayfish treatment reached Gosner's stage 25 more quickly than those not exposed to the crayfish $\left(\mathrm{F}_{1,13.5}=20.893, p<0.001\right.$; Fig. 2e).

\section{Discussion}

Phenotypic plasticity, local adaptation and maternal investment are key mechanisms that can allow withstanding alien predators through the modulation of phenotype. Our study detected strong differences in parental investment across frog populations, even though this variation was unrelated to the presence of the crayfish in the site. We evidenced that tadpole origin and exposure to the crayfish affected the development of frog embryos and larvae, suggesting that plasticity and local adaptations can play a role.

\section{Variation of maternal investment across populations}

Very limited information exists about variation of parental investment in $R$. latastei. In literature, just a few counts of the number of eggs are available, with values consistent with our study (Bernini et al. 2004, Ambrogio and Mezzadri 2018). We detected 
Table I. Candidate mixed models assessing the factors related to variation in parental investment across populations. Models are ranked according to their AIC values; models with lower AIC values are the most supported ones by the data. For all the parameters considered, the null model showed the lowest AIC values, suggesting that none of the variables has relevant support. The dependent variables of models are: a egg number; b egg volume; $\mathbf{c}$ total investment. The sign of the relationship between parental investment and variables is in parentheses. In Suppl. material 1: Table S1, we also report the significance of the variables in the three mixed models, including all the independent variables.

\begin{tabular}{|c|c|c|c|}
\hline & AIC & $\begin{array}{c}\text { Random } \\
\text { factor }\end{array}$ & Variables \\
\hline \multirow[t]{8}{*}{ A)Egg number } & 22.3 & Site & - \\
\hline & 23.4 & Site & Procambarus clarkii $(+)$ \\
\hline & 25.3 & Site & Annual mean temperature $(+)$ \\
\hline & 25.7 & Site & Monthly precipitation (-) \\
\hline & 27.3 & Site & Procambarus clarkii (+), Monthly precipitation (+) \\
\hline & 27.8 & Site & Procambarus clarkii (+), Annual mean temperature (+) \\
\hline & 29.5 & Site & Montlhy precipitation (-), Annual mean temperature (+) \\
\hline & 31.4 & Site & Procambarus clarkii $(+)$, Monthly precipitation $(+)$, Annual mean temperature $(+)$ \\
\hline \multirow[t]{8}{*}{ B)Egg volume } & -479 & Site & - \\
\hline & -465.6 & Site & Procambarus clarkii (+) \\
\hline & -464.6 & Site & Monthly precipitation (-) \\
\hline & -463.1 & Site & Annual mean temperature $(+)$ \\
\hline & -450.6 & Site & Procambarus clarkii (+), Monthly precipitation (-) \\
\hline & -449.4 & Site & Procambarus clarkii $(+)$, Annual mean temperature $(+)$ \\
\hline & -448.4 & Site & Monthly precipitation (-), Annual mean temperature $(+)$ \\
\hline & -434.5 & Site & Procambarus clarkii (+), Monthly precipitation (-), Annual mean temperature (-) \\
\hline \multirow[t]{8}{*}{ C)Total investment } & 42.9 & Site & - \\
\hline & 43.3 & Site & Procambarus clarkii $(+)$ \\
\hline & 45.3 & Site & Monthly precipitation (-) \\
\hline & 45.7 & Site & Annual mean temperature $(+)$ \\
\hline & 46.2 & Site & Procambarus clarkii (+), Monthly precipitation (+) \\
\hline & 47 & Site & Procambarus clarkii (+), Annual mean temperature (+) \\
\hline & 48.6 & Site & Monthly precipitation (-), Annual mean temperature (+) \\
\hline & 49.7 & Site & Procambarus clarkii $(+)$, Monthly precipitation $(+)$, Annual mean temperature $(+)$ \\
\hline
\end{tabular}

a very strong variation for both number of eggs and egg volume across females of different populations. Several explanations to this great variability exist, inasmuch as different selective forces and resource availability jointly act on parental investment (Roff 2002). In many cases, the variation in female conditions is a key driver of maternal investment. In amphibians, female body conditions and body size are frequently related to clutch features (Prado and Haddad 2003, Tessa et al. 2009, Chen et al. 2012, Sinsch et al. 2015). In turn, variation in size and conditions can be caused by differences in lifespan, food availability, climatic conditions and other environmental features (e.g. Reim et al. 2006; Roitberg et al. 2013). For instance, previous studies showed that females of the Monza (MZ) population are significantly larger than the ones of other populations from the study area, perhaps because of higher food availability or longevity (Ficetola et al. 2006) and this might allow them to provide better parental investments. Indeed, this hypothesis aligns with our data as Monza females have a significantly higher parental investment for all the parameters considered, if compared to the other populations (Fig. 1). 

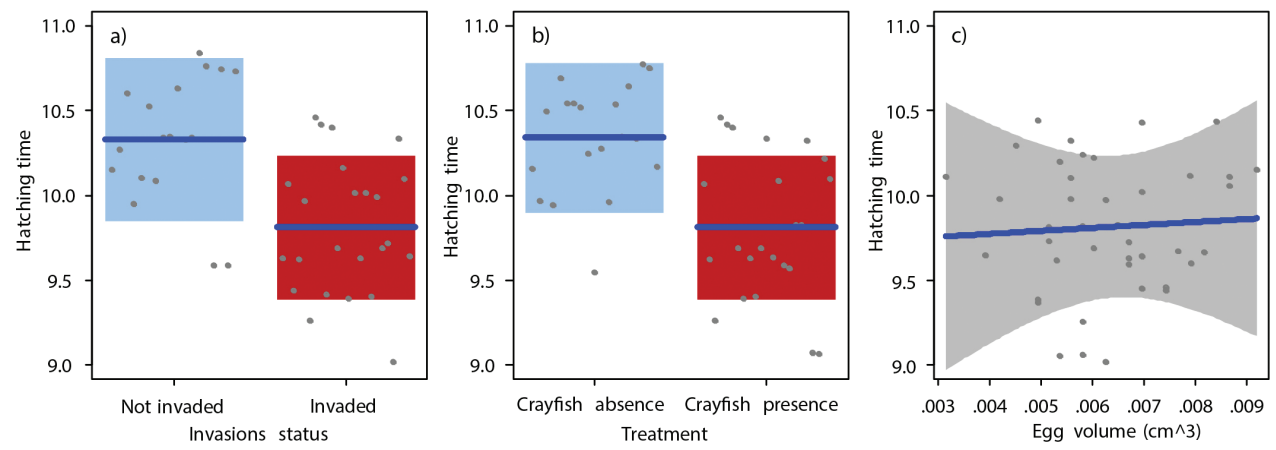

Time to reach stage 25
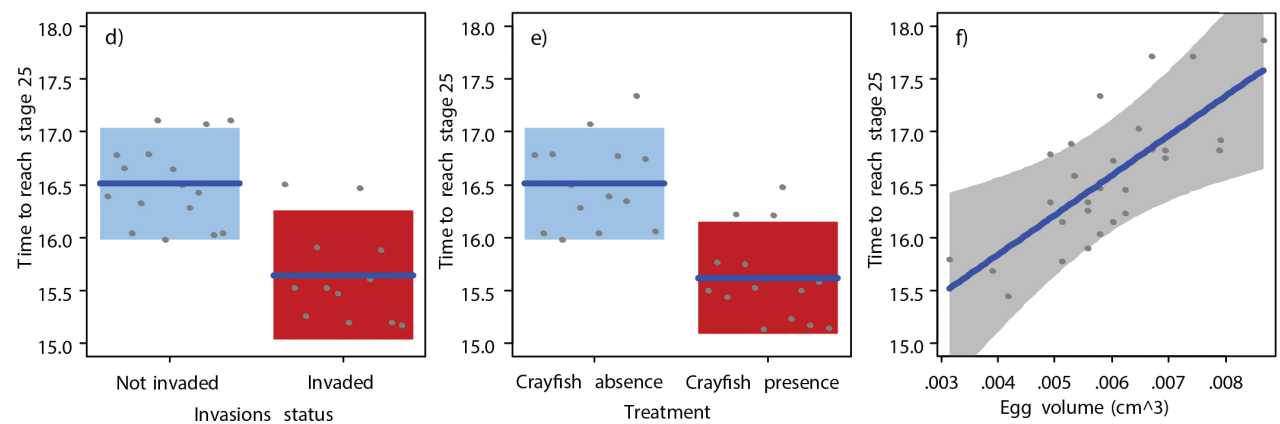

Figure 2. Hatching time and time to reach Gosner's stage 25 of Rana latastei in relation to a-d the invasion status of populations $\mathbf{b}-\mathbf{e}$ treatment during the rearing experiment and $\mathbf{c}-\mathbf{f}$ egg volume as parameter of parental investment. Red plots represent crayfish presence in the original ponds $\mathbf{a}-\mathbf{d}$ or in the treatment $\mathbf{b}, \mathbf{e}$ and blue plots represent crayfish-free sites $\mathbf{a}-\mathbf{d}$ or the rearing experiment controls $(\mathbf{b}, \mathbf{e})$. Line shows mean correlation and coloured shaded area shows the $95 \%$ confidence interval. $\mathrm{N}=42$ clutch fragments, $\mathrm{N}=239$ larvae.

Previous studies showed that differences in parental investment could provide differential fitness advantages under specific environmental conditions in amphibians (e.g. predator pressure, climate, environmental stress) (Dziminski and Ross 2005) and that females can accordingly modulate their investment (Räsänen et al. 2005). For instance, in amphibians, mothers can modify the composition of their egg coats to improve tolerance to acidic conditions in embryos (Shu et al. 2016). We did not detect relationships between maternal investment and climate, as we selected a homogeneous pool of populations to better assess the impact of the alien crayfish, but it will be interesting to assess patterns over a broader climatic gradient. Similarly, variation in maternal investment was unrelated to predator pressure. Other studies demonstrated that amphibians, depending on their life history, modulate parental care in response to geographic differences in climate and in presence of an offspring predator (Delia et 
al. 2013, Shulte et al. 2020). However, the crayfish has invaded the study area only recently, thus it is possible that the populations have had only a limited time to adapt to this predator (Lo Parrino et al. 2020).

\section{Relationships amongst invasive crayfish, maternal investment and embryo de- velopment}

Multiple factors affected development rate of Rana latastei embryos and tadpoles and crayfish presence in the pond of origin and the non-lethal exposure to the crayfish caused developmental acceleration. Egg provisioning is a key driver of the development rate in frog populations (Dziminski and Ross 2005, Ficetola et al. 2011a). In our study, there were no differences in hatching time related to the average egg volume. Even though hatchlings from clutches with smaller egg volume tended to develop faster than those with a smaller one, this relationship was affected by one single clutch with very short development time. A faster development of embryos hatched from smaller eggs is inconsistent with previous studies (Nussbaum 1985, Berven and Chadra 1988, Dziminski and Ross 2005). In fact, a rapid larval development is often assumed to be positively related to fitness and a larger parental investment is expected to provide resources that can allow embryos to reach faster large size and/or late development stages (Kaplan 1992, Warkentin 1999, Capellán and Nicieza 2006, Ficetola et al. 2011a). However, during the embryo development, the cell cleavage may need more time for larger cells than smaller ones and this could explain the faster development time of small eggs. Further studies, involving analyses of a large sample size, are required to better understand the multifaceted relationships between egg size and time of development.

We observed a significant plastic response in embryos and tadpoles reared in presence of the crayfish; individuals hatched and reached Gosner's stage 25 earlier than those unexposed to the predator. This development acceleration confirms that embryos and larvae can recognise the crayfish cues as a risk. This is the first evidence that Rana latastei is able to modify hatching phenology in response to the presence of predators and, thus, the crayfish pressure is strong enough to elicit plasticity in hatching. The coevolutionary history of species may influence the recognition of a novel predator and, therefore the expression of phenotypic plasticity. Before the crayfish invasion, the Italian agile frog was often syntopic with a native predator that is rather similar to the red swamp crayfish, i.e. the European white-clawed crayfish (Austropotamobius pallipes). In turn, the long evolutionary history with a similar native predator can facilitate responses against non-native predators. In fact, a recent study demonstrated that tadpoles of species that co-evolved with the native crayfish are able to recognise the alien crayfish and to better modulate anti-predator strategies when facing the invasive crayfish (Melotto et al. 2021b). Rapid development can be particularly important in the period from hatching to stage 25 , when tadpoles are highly vulnerable, given their limited es- 
cape ability. The faster development rate can reduce the exposure to this predator, even though tadpoles may suffer costs for other fitness-related traits (Melotto et al. 2020).

Furthermore, we detected differences between colonised and crayfish-free populations in development time. In this case, the effect of Procambarus clarkii was only evident after hatching, as tadpoles from invaded sites reached stage 25 significantly earlier, while no differences in hatching time existed. We also acknowledge that the effect of Procambarus clarkii after hatching was affected by one single clutch with particularly rapid development, highlighting the importance of additional tests. However, our findings are consistent with the conclusions of Melotto et al. (2020), despite the fact that we tested different populations in different years. This can be interpreted as local adaptation which can limit mortality and suggests that the adaptation to the crayfish occurs in invaded populations. Finally, plasticity and local adaptation often induce coherent phenotypic variation, jointly determining fitness variation across populations (Levis et al. 2018, Stamp and Hadfield 2020). Our study contributes to the growing evidence that invasive predators, as a novel selective pressure, can induce rapid evolutionary changes in native populations (Langklide 2009, Moran and Alexander 2014). Studying potential evolutionary outcomes of native prey is also important to understand the impact of invasive species and to predict potential long-term effects (Sih et al. 2010, Nunes et al. 2014b).

Despite the strong predatory pressure imposed by Procambarus clarkii, so far, the total abundance of clutches in invaded populations by the crayfish does not seem to have undergone a significant decrease (Manenti et al. 2020). Frog persistence is certainly due to the immigration of frog individuals from source populations (Manenti et al. 2020, Falaschi et al. 2021), but it is also possible that plastic and adaptive responses to this predator help to counteract the heavy predator pressure, allowing a sufficient number of tadpoles to attain metamorphosis.

In conclusion, we did not observe a significant relationship between variation in parental investment and the occurrence of a major invasive predator, nor did we detect evidence that parental investment improves development rate in this system. Nevertheless, anti-predator strategies, such as phenotypic plasticity or adaptive variations, can help native populations to reduce the impact of an alien predator. So far, most of the studies analysed variation of amphibian performance under laboratory conditions and more studies are needed to understand how these processes act in the wild. Furthermore, in a world where invasive species are increasingly widespread and abundant, continuous monitoring is required to evaluate whether these responses will allow the long-term persistence of native species.

\section{Acknowledgements}

We are thankful to Andrea Melotto for the extremely precious advice. The comments of two anonymous reviewers and of the editor allowed us to improve our study. 


\section{References}

Ambrogio A, Mezzadri S (2018) Brown frogs of Italy. Gavia Edizioni, Piacenza. 102pp.

Beebee TJC (2005) Conservation genetics of amphibians. Heredity 95: 423-427. https://doi. org/10.1038/sj.hdy.6800736

Bellard C, Cassey P, Blackburn TM (2016) Alien species as a driver of recent extinctions. Biology Letters 12(2): e20150623. https://doi.org/http://dx.doi.org/10.1098/rsbl.2015.0623

Bernini F, Gentili A, Scali S (2004) Rana latastei. In: Pianura (Ed.), Atlante degli Anfibi e dei Rettili della Lombardia. Monotipia Cremonese, e109.

Bernini F, Lapini L, Mazzotti S (2007) Rana latastei. In: Fauna d'Italia: Amphibia. Calderini, Bologna, 412-416.

Berven KA, Chadra BG (1988) The relationship among egg size, density and food level on larval development in the wood frog (Rana sylvatica). Oecologia 75: 353-362. https://doi. org/https://doi.org/10.1007/BF00378815

Breheny P, Burchett W (2017) Visualization of regression models using visreg. R Journal 9: 56-71. https://doi.org/10.32614/RJ-2017-046

Burnham KP, Anderson DR (2002) Model selection and multimodel inference: A Practical Information-Theoretic Approach. Springer Verlag, New York. 512pp.

Burraco P, Valdés AE, Orizaola G (2020) Metabolic costs of altered growth trajectories across life transitions in amphibians. Journal of Animal Ecology 89: 855-866. https://doi. org/10.1111/1365-2656.13138

Cameron GK, Martin TE (2000) Parental investment strategies in two species of nuthatch vary with stage-specific predation risk and reproductive effort. Animal Behaviour 60: 263-267. https://doi.org/10.1006/anbe.2000.1472

Capellán E, Nicieza AG (2006) Trade-offs across life stages: does predator - induced hatching plasticity reduce anuran post-metamorphic performance? Evolutionary Ecology 21: 445-458. https://doi.org/10.1007/s10682-006-9133-9

Chen W, Wu QG, Su ZX, Lu X (2012) Age, body size and clutch size of Rana kunyuensis, a subtropical frog native to China. Herpetological Journal 22: 203-206.

Cousyn C, Meester L De, Colbourne JK, Brendonck L, Verschuren D, Volckaert F (2001) Rapid, local adaptation of zooplankton behavior to changes in predation pressure in the absence of neutral genetic changes. PNAS 98: 6256-6260. https://doi.org/10.1073/ pnas. 111606798

Cruz J, Rebelo R, Crespo G (2006) Effects of an introduced crayfish, Procambarus clarkii, on the distribution of south-western Iberian amphibians in their breeding habitats. Ecography 26: 329338. https://doi.org/10.1111/j.2006.0906-7590.04333.x

Cruz MJ, Segurado P, Sousa M, Rebelo R (2008) Collapse of the amphibian community of the Paul do Boquilobo Natural Reserve (central Portugal) after the arrival of the exotic American crayfish Procambarus clarkii. Herpetological Journal 18: 197-204. Available from: https://www.researchgate.net/publication/233628801_Collapse_of_the_amphibian_community_of_the_Paul_do_Boquilobo_Natural_Reserve_central_Portugal_after_ the_arrival_of_the_exotic_American_crayfish_Procambarus_clarkii. 
Delia JRJ, Ramírez-Bautista A, Summers K (2013) Parents adjust care in response to weather conditions and egg dehydration in a Neotropical glassfrog. Behavioral Ecology and Sociobiology 67: 557-569. https://doi.org/10.1007/s00265-013-1475-z

Dziminski MA, Ross AA (2005) Patterns and fitness consequences of intraclutch variation in egg provisioning in tropical Australian frogs. Community Ecology 146: 98-109. https:// doi.org/10.1007/s00442-005-0177-2

Falaschi M, Melotto A, Manenti R, Ficetola GF (2020) Invasive Species And Amphibian Conservation. Herpetologica 76: 216-227. https://doi.org/10.1655/0018-0831-76.2.216

Falaschi M, Giachello S, Lo Parrino E, Muraro M, Manenti R, Ficetola GF (2021) Long-term drivers of persistence and colonization dynamics in spatially structured amphibian populations. Conservation Biology 35(5): 1530-1539. https://doi.org/10.1111/cobi.13686

Ferrari MCO, Gonzalo A, Messier F, Chivers DP (2007) Generalization of learned predator recognition: an experimental test and framework for future studies. Proceedings of the Royal Society B: Biological Sciences 274: 1853-1859. https://doi.org/10.1098/rspb.2007.0297

Ficetola GF, Bernardi F De (2005) Supplementation or in situ conservation? Evidence of local adaptation in the Italian agile frog Rana latastei and consequences for the management of populations. Animal Conservation 8: 33-40. https://doi.org/10.1017/ S1367943004001805

Ficetola GF, De Bernardi F (2009) Offspring size and survival in the frog Rana latastei: from among-population to within-clutch variation. Biological Journal of the Linnean Society: 845-853. https://doi.org/10.1111/j.1095-8312.2009.01229.x

Ficetola GF, Maiorano L (2016) Contrasting effects of temperature and precipitation change on amphibian phenology, abundance and performance. Oecologia 181: 683-693. https:// doi.org/10.1007/s00442-016-3610-9

Ficetola GF, Scali S, Bernardi F De (2006) The effects of isolation on fitness and morphometric: Rana latastei within the Monza Park. Atti del V Congresso Nazionale Societas Herpetologica Italica, 1998-2003.

Ficetola GF, Visaggi B, Bonardi A, Bernardi F De (2011a) Starting size and tadpole performance in the frog. Journal of Zoology 284: 15-20. https://doi.org/10.1111/j.1469-7998.2010.00770.x

Ficetola GF, Siesa ME, De Bernardi F, Padoa-Schioppa E (2012) Complex impact of an invasive crayfish on freshwater food webs. Biodiversity and Conservation 21: 2641-2651. https://doi.org/10.1007/s10531-012-0323-1

Ficetola GF, Siesa ME, Manenti R, Bottoni L, De Bernardi F, Padoa-Schioppa E (2011b) Early assessment of the impact of alien species: Differential consequences of an invasive crayfish on adult and larval amphibians. Diversity and Distributions 17: 1141-1151. https://doi. org/10.1111/j.1472-4642.2011.00797.x

Freeman AS, Byers JE (2006) Divergent induced responses to an invasive predator in marine mussel populations. Science 313: 831-833. https://doi.org/10.1126/science.1125485

Gherardi F, Renai B, Corti C (2001) Crayfish predation on tadpoles: a comparison between a native (Austropotamobius Pallipes) and an alien species (Procambarus Clarkii). Bulletin Français de la Pêche et de la Pisciculture 361: 659-668. https://doi.org/10.1051/kmae:2001011 Gosner KL (1960) A Simplified Table for Staging Anuran Embryos Larvae with Notes on Identification. Herpetologica 16: 183-190. 
Hartig F (2021) DHARMa: Residual Diagnostics for Hierarchical (Multi-Level/Mixed) Regression Models. R package 0.4.4. Available from: http://florianhartig.github.io/DHARMa.

Johnson PCD (2014) Extension of Nakagawa \& Schielzeth's R2GLMM to random slopes models. Methods in Ecology and Evolution 5: 944-946. https://doi.org/10.1111/2041-210X.12225

Kaplan RH (1992) Greater maternal investment can decrease offspring survival in the frog Bombina Orientalis. Ecological Society of America 73: 280-288. https://doi. org/10.2307/1938739

Kaplan RH (1998) Maternal effects, developmental plasticity, and life history evolution. In: Mousseau TA, Fox CW (Eds), Maternal effects as adaptations. Oxford University Press, New York, 244-260.

Kaplan RH, King EG (1997) Egg size is a developmentally plastic trait: evidence from long term studies in the frog Bombina orientalis. Herpetologica 53: 149-165.

Karger DN, Conrad O, Böhner J, Kawohl T, Kreft H, Soria-auza RW, Zimmermann NE, Linder HP, Kessler M (2017) Data Descriptor: Climatologies at high resolution for the earth's land surface areas. Nature Publishing Group 4: 1-20. https://doi.org/10.1038/sdata.2017.122

Kuznetsova A, Brockhoff PB, Christensen RHB (2017) lmerTest Package: Tests in Linear Mixed Effects Models. Journal of Statistical Software 82: 1-26. https://doi.org/10.18637/jss.v082.i13

Langklide T (2009) Invasive fire ants alter behavior and morphology of native lizards. Ecology 90: 208-217. https://doi.org/10.1890/08-0355.1

Levis NA, Isdaner AJ, Pfennig DW (2018) Morphological novelty emerges from pre-existing phenotypic plasticity. Nature Ecology \& Evolution 2: 1289-1297. https://doi. org/10.1038/s41559-018-0601-8

Manenti R, Delle Monache D, Ficetola GF (2020) Network-scale effects of invasive species on spatially-structured amphibian populations. Ecography 43: 119-127. https://doi. org/10.1111/ecog.04571

McCartney-Melstad E, Shaffer BH (2015) Amphibian molecular ecology and how it has informed conservation. Molecular Ecology 24: 5084-5109. https://doi.org/10.1111/ mec. 13391

Melotto A, Manenti R, Ficetola GF (2020) Rapid adaptation to invasive predators overwhelms natural gradients of intraspecific variation. Nature Communications 11(3608):1-10 https://doi.org/10.1038/s41467-020-17406-y

Melotto A, Ficetola GF, Pennati R, Ancona N, Manenti R (2021a) Raised by aliens: constant exposure to an invasive predator triggers morphological but not behavioural plasticity in a threatened species tadpoles. Biological Invasions 23: 3777-3793. https://doi.org/10.1007/ s10530-021-02603-7

Melotto A, Ficetola GF, Alari E, Romagnoli S, Manenti R (2021b) Visual recognition and coevolutionary history drive responses of amphibians to an invasive predator. Behavioral Ecology: 1-11. https://doi.org/10.1093/beheco/arab101

Mooney HA, Cleland EE (2001) The evolutionary impact of invasive species. Proceedings of the National Academy of Sciences of the United States of America 98: 5446-5451. https:// doi.org/10.1073/pnas.091093398

Moraga AD, Pervin E (2018) Efficient estimation of amphibian clutch size using image analysis of compressed globular egg masses. Herpetological Conservation and Biology 13: 341-346. 
Moran E V., Alexander JM (2014) Evolutionary responses to global change: lessons from invasive species. Ecology Letters 17: 637-649. https://doi.org/10.1111/ele.12262

Morrison C, Hero J (2003) Geographic variation in life-history characteristics of amphibians: a review. Journal of Animal Ecology 72: 270-279. https://doi.org/10.1046/j.13652656.2003.00696.x

Mousseau TA, Fox CW (1998) Maternal effects as adaptations. Oxford University Press, New York 13(10): 403-407. https://doi.org/10.1016/S0169-5347(98)01472-4

Nakagawa S, Schielzeth H (2013) A general and simple method for obtaining $\mathrm{R}^{2}$ from generalized linear mixed-effects models. Methods in Ecology and Evolution 4: 133-142. https:// doi.org/10.1111/j.2041-210x.2012.00261.x

Nentwig W, Bacher S, Kumschick S, Pyšek P, Vilà M (2018) More than "100 worst" alien species in Europe. Biological Invasions 20: 1611-1621. https://doi.org/10.1007/s10530017-1651-6

Nunes AL, Orizaola G, Laurila A, Rebelo R (2014a) Morphological and life-history responses of anurans to predation by an invasive crayfish: an integrative approach. Ecol Evol 4: 1491-1503. https://doi.org/10.1002/ece3.979

Nunes AL, Orizaola G, Laurila A, Rebelo R (2014b) Rapid evolution of constitutive and inducible defenses against an invasive predator. Ecology 95: 1520-1530. https:/doi. org/10.1890/13-1380.1

Nussbaum RA (1985) The evolution of parental care in Salamanders. Museum of Zoology, University of Michigan, Michigan 169: 1-60.

Orizaola G, Dahl E, Nicieza AG, Laurila A (2013) Larval life history and anti-predator strategies are affected by breeding phenology in an amphibian. Oecologia 171: 873-881. https://doi.org/10.1007/s00442-012-2456-z

Ortega Z, Mencía A, Pérez-mellado V (2017) Rapid acquisition of antipredatory responses to new predators by an insular lizard. Behavioral Ecology and Sociobiology 71: 1-9. https:// doi.org/10.1007/s00265-016-2246-4

Lo Parrino E, Ficetola GF, Manenti R, Falaschi M (2020) Thirty years of invasion: the distribution of the invasive crayfish Procambarus clarkii in Italy. Biogeographia-The Journal of Integrative Biogeography 35: 43-50. https://doi.org/10.21426/B635047157

Peacor SD, Allesina S, Riolo RL, Pascual M (2006) Phenotypic plasticity opposes species invasions by altering fitness surface. Plos biology 4: e371. https://doi.org/10.1371/journal. pbio.0040372

Pick JL, Postma E, Tschirren B (2019) The more you get, the more you give : Positive cascading effects shape the evolutionary potential of prenatal maternal investment. 3: 412-423. https://doi.org/10.1002/evl3.125

Prado CPA, Haddad CFB (2003) Testes size in Leptodactylid frogs and occurrence of multimale spawning in the genus Leptodactylus in Brazil. Journal of Herpetology 37: 354-362. https://doi.org/10.1670/0022-1511(2003)037[0354:TSILFA]2.0.CO;2

Räsänen K, Laurila A, Merilä J (2005) Maternal investment in egg size: environment- and population-specific effects on offspring performance. Population Ecology 142: 546-553. https://doi.org/10.1007/s00442-004-1762-5 
Reim C, Teuschl Y, Blanckenhorn WU (2006) Size-dependent effects of larval and adult food availability on reproductive energy allocation in the Yellow Dung Fly. Functional Ecology 20: 1012-1021. https://doi.org/10.1111/j.1365-2435.2006.01173.x

Relyea RA (2001) Morphological and behavioral plasticity of larval anurans in response to different predators. Ecology 82: 523-540. https://doi.org/10.1890/00129658(2001)082[0523:MABPOL]2.0.CO;2

Renai B, Gherardi F (2004) Predatory efficiency of crayfish: comparison between indigenous and non-indigenous species. Biological Invasions 6: 89-99. https://doi.org/10.1023/ B:BINV.0000010126.94675.50

Roff DA (2002) Life history evolution. MA: Sinauer Associates, Sunderland.

Roitberg ES, Kuranova VN, Bulakhova NA, Orvola VF, Eplanova G, Zinenko O., Shamgunova RR, Hofmann S, Yakovlev VA (2013) Variation of reproductive traits and female body size in the most widely-ranging terrestrial reptile: testing the effects of reproductive mode, lineage, and climate. Evolutionary Biology 40: 420-438. https://doi.org/10.1007/s11692-013-9247-2

Schindelin J, Rueden CT, Hiner MC, Eliceiri KW (2015) The ImageJ Ecosystem: An Open Platform for Biomedical Image Analysis. Molecular Reproduction \& Development 82: 518-529. https://doi.org/10.1002/mrd.22489

Schmidt B, Corti C, Andreone F, Ficetola GF, Poboljsaj K, Vogrin M, Manenti R, Garner TWJ (2020) Rana latastei. The IUCN Red List of Threatened Species 2020.

Shu L, Laurila A, Suters MJF, Räsänen K (2016) Molecular phenotyping of maternally mediated parallel adaptive divergence within Rana arvalis and Rana temporaria. Molecular Ecology 25: 4564-4579. https://doi.org/10.1111/mec.13786

Shulte LM, Ringler E, Rojas B, Stylnoski JL (2020) Developments in amphibian parental care research: history, present advances, and future perspectives. Herpetological Monographs 34: 71-97. https://doi.org/https://doi.org/10.1655/HERPMONOGRAPHS-D-19-00002.1

Sih A, Bolnick DI, Luttbeg B, Orrock JL, Peacor SD, Pintor LM, Preisser E, Rehage JS, Vonesh JR (2010) Predator-prey naïveté, antipredator behavior, and the ecology of predator invasions. Oikos 119: 610-621. https://doi.org/10.1111/j.1600-0706.2009.18039.x

Sinsch U, Pelster B, Ludwig G (2015) Large-scale variation of size- and age-related life-history traits in the common frog: a sensitive test case for macroecological rules. Journal of Zoology 297: 1-12. https://doi.org/10.1111/jzo.12243

Skelly DK, Freidenburg LK (2000) Effects of beaver on the thermal biology of an amphibian. Ecology Letters 3: 483-486. https://doi.org/https://doi.org/10.1111/j.1461-0248.2000.00186.x

Stamp MA, Hadfield JD (2020) The relative importance of plasticity versus genetic differentiation in explaining between population differences; a meta-analysis. Ecology Letters 23: 1432-1441. https://doi.org/10.1111/ele.13565

Tessa G, Mattioli F, Mercurio V (2009) Egg numbers and fecundity traits in nine species of Mantella poison frogs from arid grasslands and rainforests of Madagascar (Anura: Mantellidae). Madagascar Conservation \& Development 4: 113-119. https://doi.org/10.4314/ mcd.v4i2.48651

Warkentin KM (1999) Effects of hatching age on development and hatchling morphology in the red-eyed treefrog, Agalychins callidryas. Biological Journal of the Linnean Society 68: 443-470. 
Warkentin KM (2005) How do embryos assess risk? Vibrational cues in predator-induced hatching of red-eyed treefrogs. Animal Behaviour 70: 59-71. https://doi.org/10.1016/j. anbehav.2004.09.019

Weis JS, Sol D (2016) Biological invasions and animal behaviour. Cambridge University Press. https://doi.org/10.1017/CBO9781139939492

\section{Supplementary material I}

Geographic coordinates of the monitored sites and the significance of the independent variables in the three parental investment mixed models.

Authors: Martina Muraro, Samuele Romagnoli, Benedetta Barzaghi, Mattia Falaschi, Raoul Manenti, Gentile Francesco Ficetola

Data type: occurrence

Copyright notice: This dataset is made available under the Open Database License (http://opendatacommons.org/licenses/odbl/1.0/). The Open Database License $(\mathrm{ODbL})$ is a license agreement intended to allow users to freely share, modify, and use this Dataset while maintaining this same freedom for others, provided that the original source and author(s) are credited.

Link: https://doi.org/10.3897/neobiota.70.65454.suppl1

\section{Supplementary material 2}

\section{Raw data}

Authors: Martina Muraro, Samuele Romagnoli, Benedetta Barzaghi, Mattia Falaschi, Raoul Manenti, Gentile Francesco Ficetola

Data type: species data

Copyright notice: This dataset is made available under the Open Database License (http://opendatacommons.org/licenses/odbl/1.0/). The Open Database License $(\mathrm{ODbL})$ is a license agreement intended to allow users to freely share, modify, and use this Dataset while maintaining this same freedom for others, provided that the original source and author(s) are credited.

Link: https://doi.org/10.3897/neobiota.70.65454.suppl2 